\title{
Accumulating capacity of herbaceous plants of the Asteraceae and Poaceae families under technogenic soil pollution with zinc and cadmium
}

\author{
Victor Chaplygin a, Saglara Mandzhieva a, Tatiana Minkina a,*, Svetlana Sushkova a, \\ Anatolii Barahov a, Dina Nevidomskaya a, Rıdvan Kızılkaya b,c, Coşkun Gülser b, \\ Natalia Chernikova a, Mahmoud Mazarji a, Luydmila Iljina d, Vishnu Rajput a \\ a Southern Federal University, Rostov-on-Don, Russia \\ b Ondokuz Mayıs University, Faculty ofAgriculture, Department of Soil Science and Plant Nutrition, Samsun, Turkey \\ c Agrobigen Research \& Development Trade Ltd.Co, Samsun Technopark, Samsun, Turkey \\ d Federal Research Centre the Southern Scientific Centre of the Russian Academy of Sciences, Rostov-on-Don, Russia
}

\section{Article Info}

Received : 12.09 .2019

Accepted : 18.03 .2020

\begin{abstract}
In this study, the environmental monitoring of the long-term technogenic pollution zone of Novocherkassk, a region containing numerous heavy metal contaminations, was carried out. In the plants growing in the $5 \mathrm{~km}$ zone around Novocherkasskaya power station, contamination with the studied elements was revealed. The dependence of the content of $\mathrm{Zn}$ and $\mathrm{Cd}$ in herbaceous plants of the families Asteraceae and Poaceae on the distance to the source of the anthropogenic load was established. The selectivity of accumulation of metals by studied species of herbaceous plants at different levels of technogenic pollution is revealed. Achillea nobilis has the least pollutants resistant from the soil. Poa pratensis has the highest resistance to $\mathrm{Zn}$ and $\mathrm{Cd}$ pollution in terms of the set of assessment indicators. The granulometric composition of the soil has a significant impact on the availability of metals to plants.
\end{abstract}

Keywords: Heavy metals, technogenic pollution, soil-plant system.

(c) 2020 Federation of Eurasian Soil Science Societies. All rights reserved

\section{Introduction}

Environmental pollution is one of the most serious problems nowadays. These pollutants are found to be common wherever industrial enterprises or urban infrastructure presented. Emissions from chemical and energy industries are the most significant sources of pollutant release into the environment. Among the chemical elements, heavy metals (HM) are the most toxic; many of them exhibit high toxicity even in trace amount levels (Seregin and Ivanov, 2001; Zhuikova and Zinnatova, 2014). The concentration of HM in the natural environment tends to increase over time due to their persistence and non-biodegradability. For this reason, territories subject to long-term industrial pollution are important cases for research aiming at evaluating the distribution of trace elements in plant communities (Plyaskina, Ladonin, 2005; Chaplygin et al., 2018; Minkina et al., 2018). The risk associated with metals is attributed to an accumulation and toxicity characteristic which makes them remain in the soil for a long time.

Technogenic pollution mainly targets and affects the soil as the basis of any terrestrial ecosystem. The HM contamination of soils can impose major threats to agricultural sectors for a long period of time. Soil-to-crop transfer mechanism of HM is considered as the direct transformation pathway to humans. Food crops grown on the metal contaminated soil can easily uptake and accumulate metals in high quantities which in turn affect food quality and safety. To this end, special attention should be given to herbaceous plants as they represent the majority of agricultural crops and the convenient indicator for studying technogenic stress.

\footnotetext{
${ }^{*}$ Corresponding author.

Southern Federal University, pr. Stachki 194/1, Rostov-on-Don, 344090, Russia

Tel.: +79185531632
}

e-ISSN: 2147-4249

E-mail address: tminkina@mail.ru DOI: $10.18393 /$ ejss.707659 
Moreover, wild herbaceous plants as recourses of livestock feed and raw medicinal can be of a possible threat case to humans and animals.

$\mathrm{Zn}$ and $\mathrm{Cd}$ are some of the most common HM in industrial emissions related to the first hazard class. Cd and $\mathrm{Zn}$ are the most toxic elements that have multiple toxic effects on plants (Andresen and Kupper, 2013; Zhao et al., 2014; Shtangeeva et al., 2019). In addition, these elements demonstrate similar geochemical behavior and have additive properties, replacing each other in the physiological processes in plants. The results of studying the $\mathrm{Zn}-\mathrm{Cd}$ interaction are controversial since there is evidence of both antagonism and synergism between these elements during absorption and transfer (Andresen and Kupper, 2013; Zhao et al., 2014). For example, there is evidence that $\mathrm{Cd}$ is able to replace $\mathrm{Zn}$ in many vital enzymatic reactions, leading to their rupture or inhibition. It is assumed that Cd-Zn interaction mechanisms are controlled by the ratio of their concentrations in the plant habitat, the physico-chemical properties of the soil, and the biological characteristics of the absorbing plants (Kabata-Pendias and Pendias, 2001; Maksimov et al., 2018). Interdependent physico-chemical and biological factors affect the release of metal ions into soil solution and, therefore, the capacity of plants to absorb them from the soil would increase.

The aim of the work is to study the accumulation of $\mathrm{Cd}$ and $\mathrm{Zn}$ in various species of wild herbaceous plants of the Asteraceae and Poaceae families under long-term technogenic pollution.

\section{Material and Methods}

The object of the present work is soil of monitoring plots laid at a distance of 1-20 km from Novocherkassk Power Station (NPS). It is the largest enterprise in the south of Russia. This enterprise emits $1 \%$ of all pollutants into the atmosphere in the Russian Federation, over 50\% in Rostov Region, and about 90\% in Novocherkassk (Environmental Bulletin, 2018).

Monitoring plots were laid at a distance of 1-20 km from NPS. The choice of the plots was done in accordance with the air sampling plot conducted within the project in order to organize and set a sanitary protection zone of the northern industrial hub in Novocherkassk. Besides, all herbaceous plant species under investigation were grown on the chosen monitoring plots. Plant samples were collected in accordance with the prevailing north-west direction of the winds at monitoring plots No. 4, No. 8, No. 9, No. 10, and plot No. 5 , located close to this direction. Points No. 1, No. 2, No. 3, No. 7, No. 11, No. 12, No. 16, and No. 17 were laid at a distance of 1-3 km from NPS in various directions to determine the pollution level of the territories located to the side away from the prevailing wind direction. Plot No. 10 was located 400 meters from the highway. Over the decades of vehicle emissions, a significant amount of HM has entered the soil of plot No. 10, which currently continues to move from soil to plants as an additional source of anthropogenic load. Plot No. 9 was selected as the background due to its great remote location (15 km) from the NPS and the absence of additional sources of pollution.

The soils at the monitoring plots were represented by Haplic Chernozem, Meadow-Chernozemic, and alluvial soil. Haplic Chernozem (plots No. 1, No. 4, No. 5, No. 7, No. 9, No. 10, No. 16, and No. 17) has $3.6-4.2 \%$ humus content, 50.6 - 56.3\% physical clay, $40.4-44.6 \%$ silt, $0.5-1.1 \% \mathrm{CaCO}_{3}, 7.4-7.7 \mathrm{pH}, 31-36 \mathrm{cmol}(+) / \mathrm{kg}$ CEC. Meadow-chernozemic soils was monitored at plots No. 3, No. 6, No. 8, No. 11 with 4.2-5.1\% humus content, $65.3-67 \%$ physical clay, $44.0-49.3 \%$ silt, $0.2-0.7 \% \mathrm{CaCO}_{3}, 7.3-7.7 \mathrm{pH}, 31-45 \mathrm{cmol}(+) / \mathrm{kg}$ CEC. Alluvial soil of the Tuzlov river floodplain (plots No. 2, No. 12) was characterized to have $1.3-3.1 \%$ humus content, 7.5-7.9 pH, 5.9-6.9\% physical clay, 0.9-2.9\% silt, $0.4-0.5 \% \mathrm{CaCO}_{3}, 12-21 \mathrm{cmol}(+) / \mathrm{kg} \mathrm{CEC}$.

Study objects were grass plants of the Asteraceae family and Poaceae family. Plants of these families were found to be predominant at the monitoring plots including ragweed (Ambrosia artemisiifolia L.), Austrian wormwood (Artemisia austriaca Pall. Ex. Wild.), Noble yarrow (Achillea nobilis L.), and common tansy (Tanacetum vulgare L.), as well as bluegrass (Poa pratensis L.) and creeping wheatgrass (Elytrigia repens (L.) Nevski). Plant samples were collected in triplicate in the second half of June during the mass flowering stage. The sampling period was chosen due to the fact that the maximum entry of elements into the plants takes place at this stage (Ilyin and Syso, 2012).

The $\mathrm{Cd}$ and $\mathrm{Zn}$ are the metals of the first hazard class found remarkably in the emissions of NPS (Environmental Bulletin, 2018). The content of these metals was determined in the samples of plants and soils. Mineralization of plant samples was carried out by the dry ashing method according to GOST 2692994. Afterward, $\mathrm{HM}$ were extracted from ash by dissolving in a $20 \% \mathrm{HCl}$ solution with further determination using atomic absorption spectrophotometry (AAS) (Guidelines for the determination..., 1992). The HM pollution in plants was assessed by comparing the concentration of elements in plants with the maximum permissible level (MPL) of metal content in farm animals feed (Provisional maximum permissible levels..., 1987). 
The total content of $\mathrm{Cd}$ and $\mathrm{Zn}$ in soil samples was determined by the X-ray fluorescence method. The loosely bound HM compounds in soil, the most available for plants, include exchangeable, complex, and specifically adsorbed forms. The loosely bound HM compounds determined by parallel extraction using the reagents by the method of Minkina (2018): $1 \mathrm{M}$ ammonium acetate buffer $\left(\mathrm{NH}_{4} \mathrm{Ac}\right.$ ) at $\mathrm{pH} 4.8$ (soil:solution ratio = 1:5, extraction time of 18 hours) capable of extracting exchangeable metal forms; a 1\% solution of EDTA in $\mathrm{NH}_{4} \mathrm{Ac}$ at $\mathrm{pH} 4.8$ (soil: solution ratio $=1: 5$, extraction time of 18 hours) which along with the exchangeable forms of metals supposedly extract their relatively fragile complex compounds into the solution; and acidsoluble metal compounds extracted with a solution of $1 \mathrm{M} \mathrm{HCl}$ (soil: solution ratio $=1: 10$, extraction time of $1 \mathrm{~h}$ ). Based on the difference between the metal content in $\mathrm{HCl}$ and $\mathrm{NH}_{4} \mathrm{Ac}$ extracts, the content of specifically adsorbed metal compounds was calculated. The content of metals in firmly bound compounds was determined as the difference between the total amount of metals in soils and their loosely bound HM compounds. The metal content in extracts from soils was determined by AAS.

The reaction of plants to the content of elements in the medium depends on the barrier and/or non-barrier type of their uptake by the plant. The non-barrier uptake of chemical elements and their compounds to a certain concentration is a widespread phenomenon (Zhuikova and Zinnatova, 2014). Plants have barriers to the absorption of most elements due to specific physiological and biochemical mechanisms (Ghazaryan et al., 2019). Roots, as a rule, are characterized by non-barrier uptake, while the aerial part follows the barrier one.

To characterize the accumulating capacity of plants, the accumulation coefficient (AC) was used, which is presented as the ratio of the metal content in plant roots to the content of its mobile forms in the soil. This indicator reflects the root intake of metal ions from the soil into the underground organs. Loosely bound compounds of elements in the soil are taken into account for this indicator as these are the ones that are available to plants (Minkina et al., 2008). The choice of these compounds was due to the close correlation of their content in the soil with content in plants was established, while for the total content it was characterized as medium and low (Nkongolo et al., 2013). In the case of a high root barrier, the AC is $<1$. When the entry of metal ions into plant organs is not hindered, the AC is $\geq 1$.

The distribution of metals in plant organs was assessed by the value of the distribution coefficient (DC) as it calculated by the ratio of HM content in the root system to the aerial part of the plant (Kabata-Pendias, Pendias, 2001).

\section{Results and Discussion}

The studies of soils at monitoring plots revealed the presence of long-term HM pollution. Plots located at a distance of $5 \mathrm{~km}$ to the north-west of the NPS and those adjacent to them are characterized by a content of total $\mathrm{Zn}$ exceeds approximate permissible concentrations in 1.1-1.4 times (GN 2.1.7.2511-09, 2009) (Figure 1). It was found that the content of $\mathrm{Cd}$ exchangeable forms exceeded the maximum permissible concentrations in 1.2-7.0 times (GN 2.1.7.2042-06, 2006), while no pollution was observed in terms of total content, which was probably due to the high mobility of the element in the soil. Loosely bound compounds were accounted for $12-57 \%$ of total Zn content and $22.5-59.5 \%$ total Cd content (Figure 2). Monitoring plots No. 4, No. 5, No. 6 and No. 7, which were closest to the source of emissions in the north-west, north-northwest and north directions, demonstrated the maximum content of loosely bound compounds of HM. This indicated an increase in the mobility of elements in soils under technogenic load. A general tendency toward an increase in the portion of more mobile forms (exchangeable and complex forms) with the rise in the total HM content is observed. The HM concentration at the plots farthest from the emission source corresponded to their background level. A larger part of the HM (95-98\%) is firmly fixed by the soil components. Loosely bound Cd compounds were mainly represented by specifically metal adsorbed form.

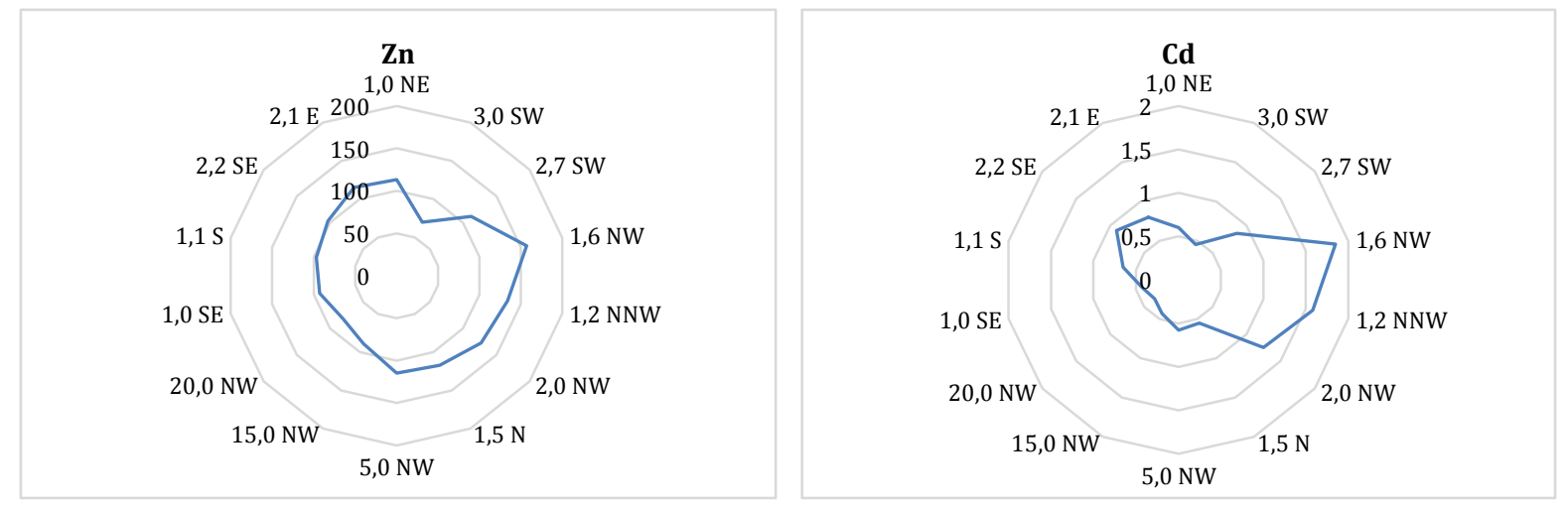

Figure 1. Total content of $\mathrm{Zn}$ and $\mathrm{Cd}$ in $0-20 \mathrm{~cm}$ soil layer of the different monitoring plots, $\mathrm{mg} \mathrm{kg}^{-1}$ 

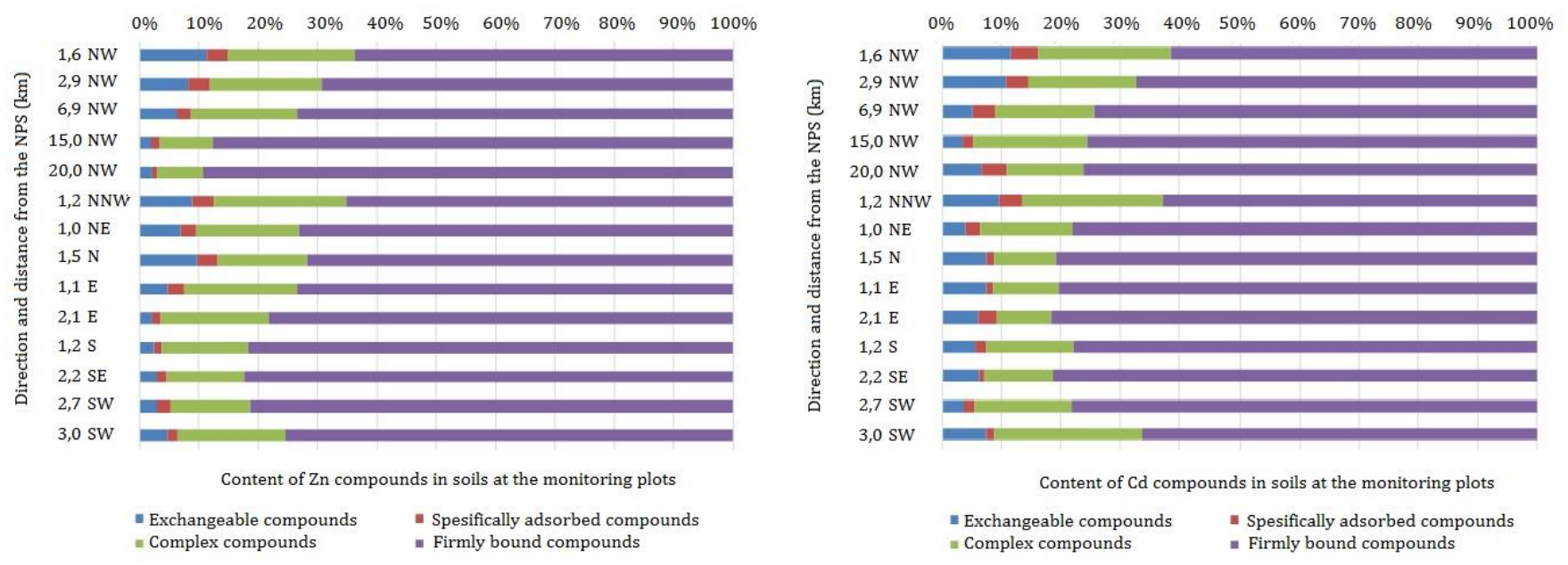

Figure 2. The content of $\mathrm{Zn}$ and $\mathrm{Cd}$ compounds in soils at the monitoring plots, \%

The dependence of the metal content in soils on the particle size distribution was determined. The content of elements in alluvial sandy soils at plots No. 2 and No. 12 was lower than at neighboring monitoring plots located approximately at the same distance from the NPS and represented by chernozem and meadowchernozemic soils of heavy loam and light clay size distribution (Figure 1).

The dependence between HM content in plants and the level of the anthropogenic load was also established. With the distance from the NPS the content of elements in plants decreases to their average content in grassy plants of Rostov Region (Environmental Bulletin, 2018). Due to the selectivity of the element accumulation, different types of plants accumulated various amounts of HM in their organs (Minkina et al., 2018), therefore, representatives of several herbaceous plant species were studied (Figure 3, 4).
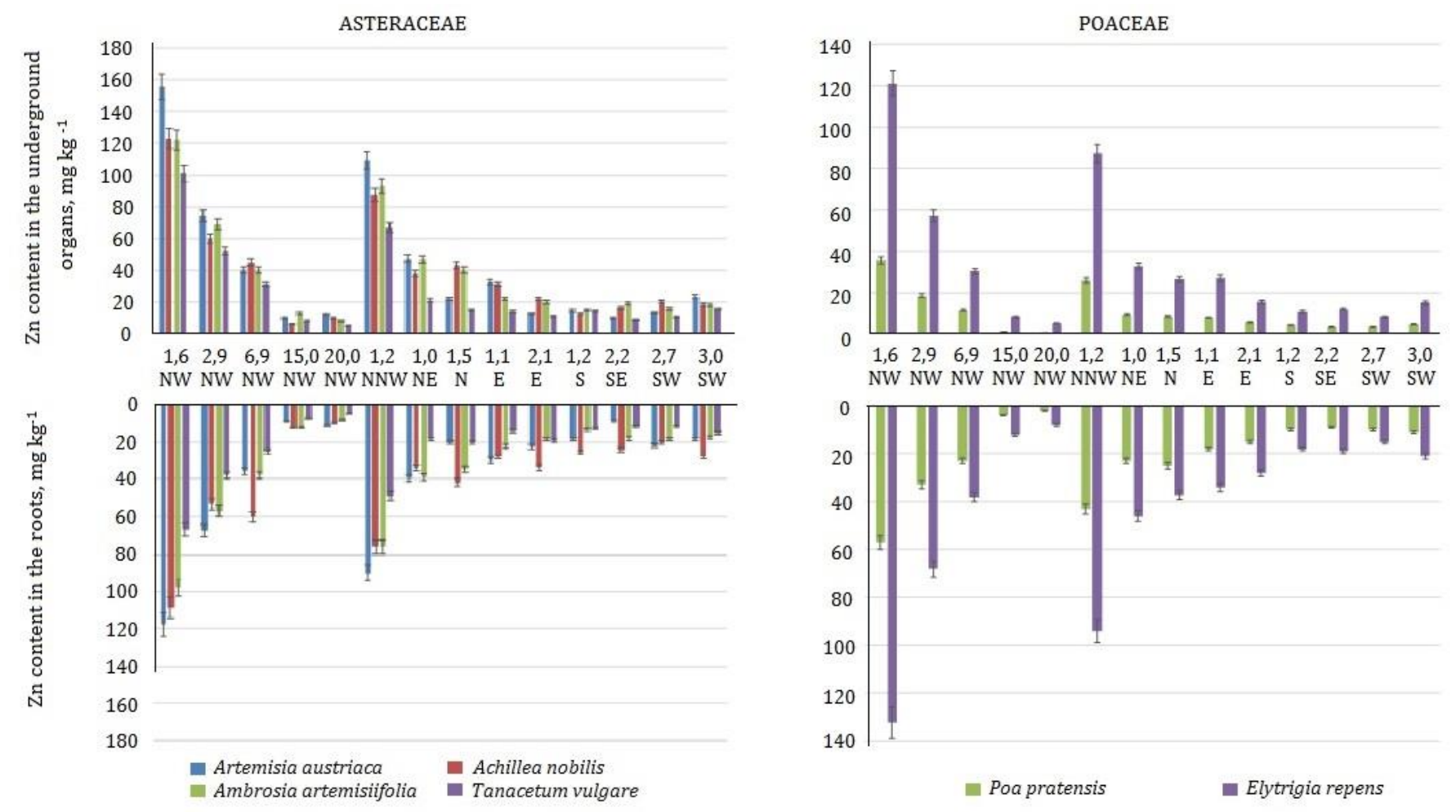

Figure 3. The $\mathrm{Zn}$ content in various species of wild herbaceous plants at the different monitoring plots, $\mathrm{mg} \mathrm{kg}{ }^{-1}$

At monitoring plots No. 4, No. 5, and No. 6, where the greatest technogenic load experienced, Zn pollution (from 1.2 to 3.1 MPL) was established for all plant species studied, except for bluegrass. It is important to note that the MPL excess for this element was recorded only under maximum technogenic load, while at the other monitoring plots, Zn content corresponded or did not exceed the background content (Figure 3). Plants of the Asteraceae family demonstrated a higher Zn content, compared with the Poaceae family. Zn accumulated mainly in the aerial parts of Asteraceae family plants, while plants in the Poaceae family were characterized by $\mathrm{Zn}$ accumulation predominantly in the root system. The highest metal content was characteristic for wormwood; the minimum $\mathrm{Zn}$ content was found in bluegrass. The content of $\mathrm{Zn}$ in plants 
was two times higher than that of $\mathrm{Cd}$. This could be associated with the high demand of $\mathrm{Zn}$ in plants for performing a number of biological functions (Figure 3, 4).
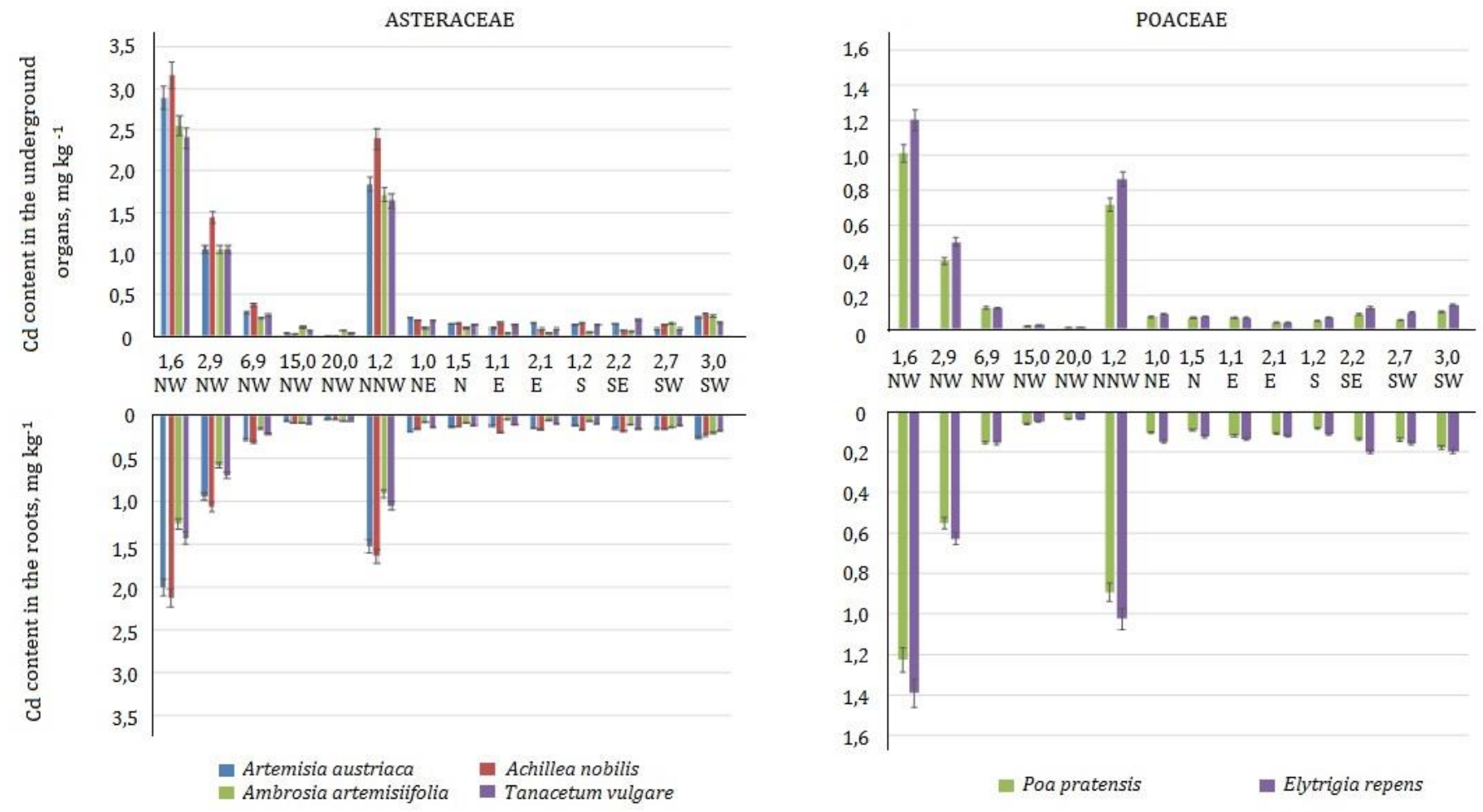

Figure 4. The content of $\mathrm{Cd}$ in various species of wild herbaceous plants at the different monitoring plots, $\mathrm{mg} \mathrm{kg}^{-1}$

The excess of MPL for Cd was detected in all studied plant species. It was found to be 3.5-9.6 times for wormwood, 1.3-10.5 times for yarrow, 3.5-8.5 times for ragweed, 3.5-8.0 times for tansy, 2.7-4.0 times for wheatgrass and 1.3-3.4 times for bluegrass. Under Cd pollution, a clear localization of contaminated plants was also observed at monitoring plots that were severely affected by technogenic pollution. Wormwood and yarrow demonstrated either slight excesses of MPL for Cd or relatively close to the threshold within the entire $5 \mathrm{~km}$ zone. $\mathrm{Cd}$, similar to $\mathrm{Zn}$, was predominantly accumulated in the aerial parts of plants of the Asteraceae family and in the root system of the Poaceae family. The maximum concentration of Cd was detected in yarrow, while the minimum was observed in bluegrass.

The selectivity of accumulating HM by plants depending on the level of anthropogenic load and plant species along with their associated biological barriers (Kabata-Pendias and Pendias, 2001). They are created by plants to regulate the number of nutrients entering the body in order to avoid accumulating phytotoxic concentrations of HMs. They identify the resistance of plants to anthropogenic pollution. The first of these barriers is located at the soil-root system boundary. The effect of this barrier determines the amount of HM in which the plants can uptake since the soil is the main source of elements entering them. For this reason, the entry of $\mathrm{Zn}$ and Cd into plants from the soil was studied.

The most objective of the indicators that makes it possible to evaluate the effectiveness of "soil-root system" barrier is AC. Based on the AC data obtained, the maximum translocation of HM from the soil to the plants was observed at the plots located in accordance with the prevailing wind direction and within $5 \mathrm{~km}$ from the NPS (Figure 5). For Zn, AC>1 was observed in all plants, except tansy and bluegrass. The highest coefficient values were obtained for creeping wheatgrass, while bluegrass was characterized by minimum $\mathrm{Zn}$ accumulation. This indicates that the selectivity of the element accumulation by plants is manifested not only at the family level but also at the species level. A possible reason for the feature established for tansy may be the atmospheric influx of HM into the plant, which is not taken into account by the value of AC.

Values of $\mathrm{AC}>1$ for $\mathrm{Cd}$ were calculated for all plants under the investigation, which indicates the active uptake of HM from the soil. The noble yarrow was characterized by the highest values of $\mathrm{AC}$ for $\mathrm{Cd}$ and had $\mathrm{AC}>1$ at most monitoring plots. The lowest coefficient values were determined for bluegrass, as in the case of AC for Zn. Wormwood and yarrow had significantly higher AC values, compared with the rest of the plants under the study. Tansy and ragweed had approximately the same level of AC values equivalent to those of bluegrass and wheatgrass. This observation confirms the fact that the level of anthropogenic load and the plant species, as well as the properties of the element itself, impact the entry of HM into plants. 

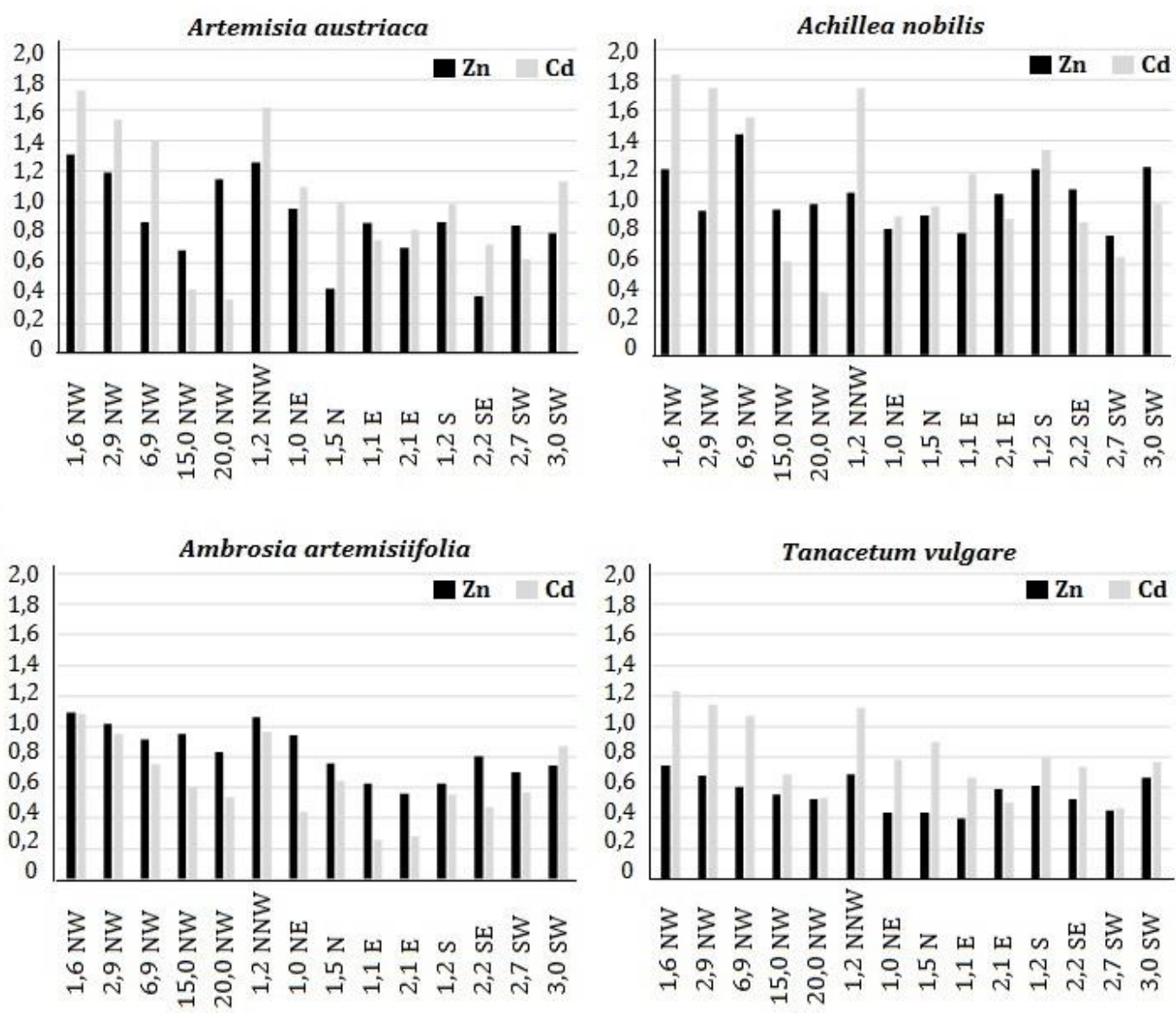

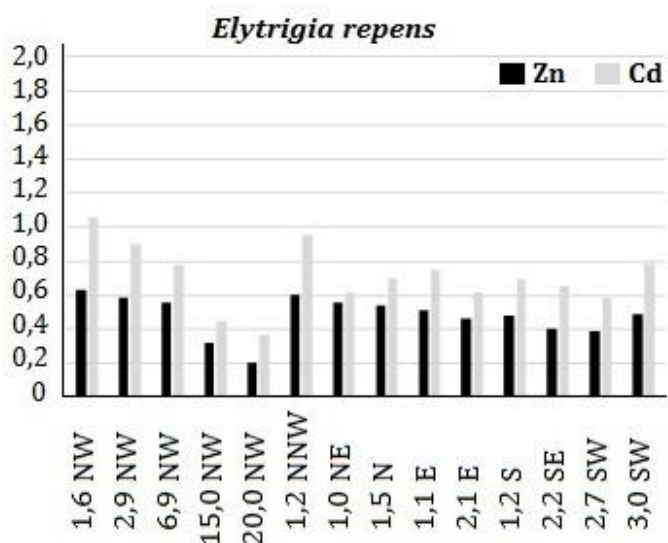

Direction and distance from the NPS $(\mathrm{km})$

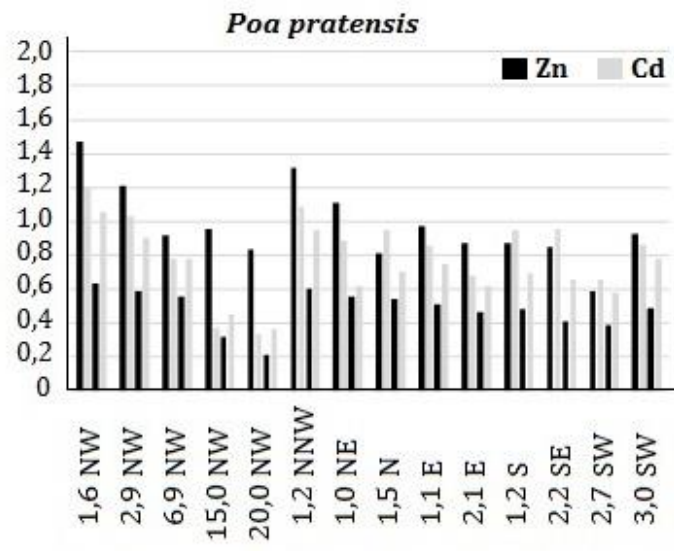

Direction and distance from the NPS $(\mathrm{km})$

Figure 5. The accumulation coefficient (AC) of $\mathrm{Zn}$ and $\mathrm{Cd}$ in various species of wild herbaceous plants at the different monitoring plots

Another important factor affecting the accumulation of HM by a plant is the particle size distribution of the soil (Burachevskaya et al., 2019). At plots No. 2 and No. 12, represented by alluvial soil, a higher accumulation of $\mathrm{Zn}$ and $\mathrm{Cd}$ in plants was observed compared to neighboring plots. This dependence was more pronounced in plants of the Poaceae family. Among the Asteraceae family, yarrow and tansy demonstrated this dependency most clearly. Apparently, this was due to the fact that soils of light particle size distribution did not retain the fixing $\mathrm{HM}$ well, leaving them in forms available to plants.

The second barrier to HM entry into plants is located at the root system - aboveground part border. It determines the nature of element distribution in the organs of the plant and indicates the internal stability of the plant. The calculated DC values make possible to assess the degree of translocation of elements from the root system to the aerial part of the plants under the study (Table 1). It was established that although $\mathrm{Zn}$ translocation from plant roots to the aboveground organs varied depending on the level of anthropogenic load, its general tendencies remained the same for all plant species under study. At monitoring plots experiencing the greatest technogenic stress (No. 4, No. 5 and No. 6), tansy, wormwood, and ragweed were characterized by maximum DC values. The bluegrass was observed at minimum values. At plot No. 9, 
considered as the background, maximum and minimum DC values were distributed in a similar way. In general, ragweed, tansy, and wormwood demonstrated the most intense $\mathrm{Zn}$ translocation from the roots, whereas bluegrass and wheatgrass possessed the least intense $\mathrm{Zn}$ translocation. It should be noted that although tansy, along with wormwood and ragweed, had a high $\mathrm{Zn}$ content in the aerial parts and one of the highest DC indices, the AC for this plant was significantly lower than that of other representatives of the Asteraceae family. This pattern indicates a lower resistance of the tansy to technogenic pollution with $\mathrm{Zn}$.

Table 1. The distribution coefficient (DC) of Zn in various types of wild herbaceous plants at the different monitoring plot

\begin{tabular}{|c|c|c|c|c|c|c|c|}
\hline \multicolumn{2}{|c|}{$\begin{array}{l}\text { Plot no., direction and } \\
\text { distance from the NPS (km) }\end{array}$} & $\begin{array}{l}\text { Artemisia } \\
\text { austriaca }\end{array}$ & $\begin{array}{c}\text { Achillea } \\
\text { nobilis }\end{array}$ & $\begin{array}{c}\text { Poa } \\
\text { pratensis }\end{array}$ & $\begin{array}{c}\text { Ambrosia } \\
\text { artemisiifolia }\end{array}$ & $\begin{array}{l}\text { Tanacetum } \\
\text { vulgare }\end{array}$ & $\begin{array}{c}\text { Elytrigia } \\
\text { repens }\end{array}$ \\
\hline \multicolumn{8}{|c|}{$\mathrm{Zn}$} \\
\hline 1. & $1.0 \mathrm{NE}$ & 1.19 & 1.11 & 0.40 & 1.21 & 1.17 & 0.71 \\
\hline 2. & $3.0 \mathrm{SW}$ & 1.30 & 0.65 & 0.41 & 1.06 & 1.02 & 0.71 \\
\hline 3. & $2.7 \mathrm{SW}$ & 0.62 & 1.02 & 0.34 & 0.89 & 0.91 & 0.53 \\
\hline 4. & $1.6 \mathrm{NW}$ & 1.32 & 1.13 & 0.63 & 1.24 & 1.51 & 0.92 \\
\hline 5. & $1.2 \mathrm{NNW}$ & 1.21 & 1.15 & 0.60 & 1.22 & 1.37 & 0.93 \\
\hline 6. & $2.9 \mathrm{NW}$ & 1.11 & 1.13 & 0.55 & 1.21 & 1.37 & 0.84 \\
\hline 7. & $1.5 \mathrm{~N}$ & 1.10 & 1.02 & 0.34 & 1.14 & 0.75 & 0.71 \\
\hline 8. & $6.9 \mathrm{NW}$ & 1.12 & 0.75 & 0.50 & 1.05 & 1.24 & 0.80 \\
\hline 9. & $15.0 \mathrm{NW}$ & 1.16 & 0.50 & 0.25 & 1.08 & 1.14 & 0.67 \\
\hline 10. & $20.0 \mathrm{NW}$ & 1.09 & 1.05 & 0.15 & 1.00 & 1.00 & 0.63 \\
\hline 11. & $1.2 \mathrm{~S}$ & 0.81 & 0.50 & 0.41 & 1.15 & 1.14 & 0.60 \\
\hline 12. & $1.1 \mathrm{E}$ & 1.09 & 1.11 & 0.43 & 1.00 & 1.00 & 0.79 \\
\hline 13. & $2.2 \mathrm{SE}$ & 1.19 & 0.68 & 0.38 & 1.06 & 0.76 & 0.63 \\
\hline 14. & $2.1 \mathrm{E}$ & 0.57 & 0.65 & 0.37 & 1.11 & 0.58 & 0.55 \\
\hline \multicolumn{8}{|c|}{$\mathrm{Cd}$} \\
\hline 1. & $1.0 \mathrm{NE}$ & 1.13 & 1.21 & 0.69 & 1.39 & 1.35 & 0.60 \\
\hline 2. & $3.0 \mathrm{SW}$ & 0.88 & 1.19 & 0.57 & 1.22 & 0.92 & 0.71 \\
\hline 3. & $2.7 \mathrm{SW}$ & 0.58 & 0.87 & 0.39 & 1.09 & 0.83 & 0.61 \\
\hline 4. & $1.6 \mathrm{NW}$ & 1.44 & 1.49 & 0.82 & 2.02 & 1.68 & 0.86 \\
\hline 5. & $1.2 \mathrm{NNW}$ & 1.21 & 1.46 & 0.80 & 1.88 & 1.56 & 0.84 \\
\hline 6. & $2.9 \mathrm{NW}$ & 1.12 & 1.36 & 0.71 & 1.81 & 1.51 & 0.80 \\
\hline 7. & $1.5 \mathrm{~N}$ & 1.07 & 1.19 & 0.73 & 1.16 & 1.13 & 0.61 \\
\hline 8. & $6.9 \mathrm{NW}$ & 1.04 & 1.24 & 0.81 & 1.47 & 1.19 & 0.79 \\
\hline 9. & $15.0 \mathrm{NW}$ & 0.72 & 0.44 & 0.37 & 1.30 & 0.84 & 0.55 \\
\hline 10. & $20.0 \mathrm{NW}$ & 0.36 & 0.33 & 0.31 & 1.41 & 0.79 & 0.34 \\
\hline 11. & $1.2 \mathrm{~S}$ & 1.10 & 0.98 & 0.62 & 0.94 & 1.39 & 0.62 \\
\hline 12. & $1.1 \mathrm{E}$ & 0.83 & 0.84 & 0.57 & 1.16 & 1.19 & 0.49 \\
\hline 13. & $2.2 \mathrm{SE}$ & 0.97 & 0.45 & 0.62 & 0.69 & 1.27 & 0.62 \\
\hline 14. & $2.1 \mathrm{E}$ & 1.03 & 0.55 & 0.38 & 0.88 & 1.03 & 0.33 \\
\hline
\end{tabular}

Under technogenic pollution, the highest Cd translocation was observed in ragweed, yarrow, and tansy, and the lowest level was established for bluegrass (Table 1). At plot No. 9, ragweed, tansy, and wormwood had the maximum DC values while bluegrass was characterized by the least intense Cd translocation from the roots to the aerial part as in case of the increased anthropogenic load. In general, the highest and lowest Cd translocation among the studied species was established for ragweed and bluegrass, respectively. Thus, for the plants of the Asteraceae family, there was a significantly higher accumulation of $\mathrm{Zn}$ and $\mathrm{Cd}$, as well as translocation of these HM from roots to aboveground organs, compared to the Poaceae family. Bluegrass (Poa pratensis L.) according to this indicator was the most resistant plant to HM pollution.

\section{Conclusion}

High levels of soil pollution lead to excessive accumulation of heavy metals in the plants. Long-term technogenic pollution is established at NPS. The negative effects of emissions from NPS affect wild herbaceous plants growing within a $5 \mathrm{~km}$ zone, primarily in the north-west direction. The $\mathrm{Zn}$ and $\mathrm{Cd}$ were found to be the priority soil contaminants of the territories under study. Plant species specificity with respect to the studied pollutants was revealed. Plants of the Asteraceae family were found to accumulate larger amounts of HM than that of the Poaceae family. The Asteraceae family demonstrated the predominant accumulation of $\mathrm{Zn}$ and $\mathrm{Cd}$ in the aerial part, while the Poaceae family accumulates them in the root system. Ragweed, wormwood, and tansy were found to be characterized by the greatest translocation of elements from the roots to the aboveground parts, as a consequence, demonstrating low resistance to HM pollution. The least resistance to HM entry from the soil is established for yarrow noble. Bluegrass demonstrates the 
highest resistance to $\mathrm{Zn}$ and $\mathrm{Cd}$ pollution in terms of the aggregate DC and AC indicators. The light granulometric composition of soil contributed to greater HM availability to plants. Along with general patterns, specific features of $\mathrm{Zn}$ and $\mathrm{Cd}$ accumulation by plants were revealed. The $\mathrm{Cd}$ exhibited a noticeably greater mobility in soils than $\mathrm{Zn}$, which led to a higher level of plant contamination and higher AC values. A successful integrated approach suggested in for studying $\mathrm{Zn}$ and $\mathrm{Cd}$ accumulation along with consideration of plant barrier functions pave the way to successfully predict the negative effects of technogenic environmental pollution in the future.

\section{Acknowledgments}

The research was supported by the project of the Ministry of Science and Higher Education of the Russian Federation within the framework of the state task of the Southern Federal University for 2020-2022 (№ FENW-2020-0028).

\section{References}

Andresen, E., Küpper, H., 2013. Cadmium toxicity in plants. In: Cadmium: from toxicity to essentiality. Sigel, A., Sigel, H., Sigel, R.C.O. (Eds.). Springer, Dordrecht. pp. 395-413

Burachevskaya, M., Minkina, T., Mandzhieva, S., Bauer, T., Chaplygin, V., Zamulina, I., Sushkova, S., Fedorenko, A., Ghazaryan, K., Movsesyan, H., Makhinya, D., 2019. Study of copper, lead, and zinc speciation in the Haplic Chernozem surrounding coal-fired power plant. Applied Geochemistry 104: 102-108.

Chaplygin, V., Minkina, T., Mandzhieva, S., Burachevskaya, M., Sushkova, S., Poluektov, E., Antonenko, E., Kumacheva, V., 2018. The effect of technogenic emissions on the heavy metals accumulation by herbaceous plants. Environmental Monitoring and Assessment 190(3): 124.

Environmental Bulletin of the Don: On the state of the environment and natural resources of the Rostov region in 2017. 2018. Rostov-on-Don, Russian Federation. 283p. [in Russian].

Ghazaryan, K.A., Movsesyan, H.S., Minkina, T.M., Sushkova, S.N., Rajput, V.D., 2019.. The identification of phytoextraction potential of Melilotus officinalis and Amaranthus retroflexus growing on copper- and molybdenum-polluted soils. Environmental Geochemistry and Health [in press]

GN 2.1.7.2042-06. 2006. Maximum permissible concentrations of chemicals in the soil: Hygienic standards. Rospotrebnadzor, Moscow, Russian Federation. [in Russian].

GN 2.1.7.2511-09. 2009. Approximate permissible concentrations of chemicals in soil: Hygiene standards. Rospotrebnadzor, Moscow, Russian Federation. [in Russian].

Guidelines for the determination of heavy metals in farmland soils and crop production. 1992. Moscow, Russian Federation. TSINA0. 61p. [in Russian].

Ilyin, V.B., Syso, A.I., 2012. Heavy metals and nonmetals in the soil-plant system. Siberian branch RAS publishing House, Novosibirsk. Russian Federation. 220 p. [in Russian].

Kabata-Pendias, A., Pendias, H. (2001). Trace elements in soils and plants. CRC Press, Boca Raton. 403p.

Maksimov, N., Evmenyeva, A., Breygina, M. Yermakov, I., 2018. The role of reactive oxygen species in pollen germination in Picea pungens (blue spruce). Plant Reproduction 31(4): 357-365.

Minkina, T.M., Mandzhieva, S.S., Burachevskaya, M.V., Bauer, T.V., Sushkova, S.N., 2018. Method of determining loosely bound compounds of heavy metals in the soil. MethodsX 5: 217-226.

Minkina, T.M., Mandzhieva, S.S., Chaplygin, V.A., Nazarenko, O.G., Maksimov, A.Y., Zamulina, I.V., Burachevskaya, M.V., Sushkova, S.N., 2018. Accumulation of heavy metals by forb steppe vegetation according to long-term monitoring data. Arid Ecosystems 8(3): 190-202.

Minkina, T.M., Motuzova, G.V., Mandzhieva, S.S., 2008. Barrier functions of the soil-plant system. Moscow University Soil Science Bulletin 63(2): 45-50.

Nkongolo, K.K., Spiers, G., Beckett, P., Narendrula, R., Theriault, G., Tran, A., Kalubi, K.N., 2013. Long-term effects of liming on soil chemistry in stable and eroded upland areas in a mining region. Water, Air, \& Soil Pollution 224(7): 1618.

Plyaskina, O.V., Ladonin, D.V., 2005. Compounds of heavy metals in granulometric fractions of certain soil types. Moscow University Soil Science Bulletin 4:36-43. [in Russian].

Provisional maximum permissible levels (MPL) for some chemical elements and gossypol in forage for farm animals and feed additives, 1987. Moscow, Russian Federation. [in Russian].

Seregin, I.V., Ivanov, V.B., 2001. Physiological aspects of cadmium and lead toxic effects on higher plants. Russian Journal of Plant Physiology 48(4): 523-544.

Shtangeeva, I., Viksna, A., Grebnevs, V., 2020. Geochemical (soil) and phylogenetic (plant taxa) factors affecting accumulation of macro-and trace elements in three natural plant species. Environmental Geochemistry and Health 42(1): 209-219.

Zhao, Z.J., Nan, Z.R., Wang, Z.W., Yang, Y.M., Shimizu, M. (2014). Interaction between Cd and Pb in the soil-plant system: a case study of an arid oasis soil-cole system. Journal of Arid Land 6(1): 59-68.

Zhuikova, T.V., Zinnatova, E.R., 2014. Accumulating capacity of plants in conditions of technogenic soil pollution with heavy metals. Volga Ecological Journal 2: 196-207 [in Russian]. 